Scientił studia, São Paulo, v. 10, n. 3, p. 593-612, 2012

\title{
ist \\ Sistemática filogenética hennigiana: revolução ou mudança no interior de um paradigma?
}

Charles Morphy Dias Santos \& Bruna Klassa

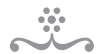

RESUMO

A sistemática filogenética, método de reconstrução de árvores evolutivas criado por Willi Hennig em 1955 e ampliado em 1966, é frequentemente considerada um novo paradigma que revolucionou as classificações biológicas quando comparado às escolas de sistemática anteriores, como a taxonomia evolutiva. Tal abordagem da história da sistemática é baseada principalmente na visão de Kuhn sobre o progresso do conhecimento científico. No entanto, podemos questionar a validade desse status revolucionário - na visão kuhniana - atribuído à filogenética hennigiana. Aqui, discutimos os atributos compartilhados pela sistemática filogenética e taxonomia evolutiva, ambas profundamente relacionadas à teoria evolutiva de Darwin-Wallace, e porque o método de Hennig é de fato um desenvolvimento da proposta para as classificações biológicas de Mayr e Simpson, explícita na teoria sintética da evolução dos anos 1930 e 1940. Nesse sentido, elas ajustam-se à visão popperiana de "seleção natural" das hipóteses científicas. Mais ainda, a sistemática filogenética é um método científico robusto e objetivo, características que lhe permitem "sobreviver" na luta pela existência com outras escolas de sistemática.

Palavras-Ghave $\bullet$ Kuhn. Hennig. Paradigma. Taxonomia evolutiva. Sistemática filogenética.

\section{INTRODUÇÃO}

Muito já foi considerado no que diz respeito ao desenvolvimento do conhecimento científico. Em Conjecturas e refutações (2008 [1980]), Karl Popper descreve o dilema que o fez voltar-se para a busca pela distinção entre ciência e pseudociência, por meio de uma breve comparação entre a teoria da relatividade de Albert Einstein e a teoria da história de Karl Marx, a psicanálise de Sigmund Freud e a psicologia individual de Alfred Adler, referindo-se a isso da seguinte maneira.

Essas teorias [de Einstein, Marx, Freud e Adler] pareciam poder explicar praticamente tudo em seus respectivos campos (...). O mundo estava repleto de verificações da teoria (...). Era precisamente esse fato que constituía o mais forte 
argumento em seu favor. Comecei a perceber aos poucos que essa força aparente era, na verdade, uma fraqueza (Popper, 2008 [1980], p. 64).

De maneira sintética, o critério encontrado por Popper para solucionar esse problema de demarcação do conhecimento científico foi a testabilidade ou falseabilidade das asserções (Popper, 1959). Uma vez que a verdade científica é inatingível, o que a proposta popperiana defende é o teste exaustivo das hipóteses científicas através da formulação de conjecturas ou proposições de caráter universal, a fim de identificar aquelas mais resistentes às críticas e atribuir-lhes certo grau de credibilidade ou proximidade da realidade. O desenvolvimento científico é, portanto, racional e acontece por meio de um processo gradual e constante de substituição de teorias menos satisfatórias frente aos testes por outras mais satisfatórias e de maior conteúdo informativo.

Em 1962, na primeira edição de A estrutura das revoluções científicas, Thomas Kuhn propôs uma concepção diferente sobre a dinâmica do conhecimento científico. Ele introduziu o termo "paradigma" como sendo um "guia" consensual que trata dos fundamentos da prática de pesquisa (ou exercício da ciência normal), determinado por fatores objetivos e subjetivos e, por isso, incomensurável com qualquer outro. Para Kuhn, um paradigma corresponderia a um conjunto de realizações universalmente reconhecidas, o qual, por certo período histórico, fornece problemas, novas questões e soluções para a comunidade de pesquisadores. O desenvolvimento científico ocorre de duas maneiras, normal e revolucionária. A ciência normal "é aquilo que produz os tijolos que a pesquisa científica está sempre adicionando ao crescente acervo de conhecimento científico" (Kuhn, 2006, p. 23). O tipo revolucionário ocorre quando da ruptura completa do paradigma vigente em uma dada área, caracterizando um processo descontinuísta pautado por grandes revoluções conceituais. Segundo essa visão, a ciência normal seria uma atividade de resolução de problemas: uma comunidade científica, ao aceitar um paradigma, adquire igualmente um critério para a escolha de problemas que poderão ser solucionados dentro dos seus limites. O período revolucionário emerge quando o consenso paradigmático começa a ser questionado, quando novas teorias, surgidas nesse contexto, exigiriam grandes alterações nos problemas e técnicas da ciência normal (cf. Kuhn, 1962).

Intimamente ligada à teoria da evolução, a sistemática filogenética, inicialmente proposta pelo entomólogo alemão Willi Hennig em sua obra de 1950, posteriormente traduzida para o inglês e ampliada (Hennig, 1966), é considerada o paradigma contemporâneo no campo da taxonomia e sistemática biológica (cf. Schuh \& Brower, 2009). Tendo em vista sua importância para o entendimento da diversidade orgânica à luz da evolução e para a reconstrução criteriosa de cenários histórico-evolutivos, a sistemática filogenética - também chamada cladística - é uma ferramenta importante para a 
unificação das diversas áreas das ciências biológicas, propiciando estudos mais completos de biologia comparada. Muitos autores atribuem ao método hennigiano um status revolucionário (cf. Williams \& Forey, 2004; Terra, 2010), como se ele correspondesse a uma ruptura completa do paradigma representado pela taxonomia evolutiva, cuja visão era calcada nos trabalhos de Ernst Mayr e associados (1953). O objetivo do presente trabalho é discutir se o eclipse da visão clássica de sistemática e a adesão à proposta de Hennig devem ser pensados como uma revolução no sentido kuhniano ou se precisam ser vistos como mudanças no interior de um paradigma representado pela teoria sintética da evolução (cf. Mayr \& Provine, 1980). Dada a propensão de Hennig a ver-se como continuando os trabalhos de Mayr e Simpson (cf. Hennig, 1966) e partindo das idiossincrasias do seu método, defenderemos que a sistemática filogenética corresponde a um desenvolvimento do pensamento sistemático de Darwin (1859), que fundamentou diferentes escolas classificatórias do século xx.

\section{Evolução e Sistemática}

Em 1859, Charles Darwin publicou a obra que inaugurou o pensamento evolutivo moderno (cf. Mayr \& Bock, 2002; Gould, 2002; Bowler, 2003; Ruse \& Travis, 2009). No ano anterior, já haviam sido divulgados os artigos que tratavam do que viria a tornar-se a teoria central das ciências biológicas, ou seja, a evolução via seleção natural (cf. Darwin, 1858; Wallace, 1855, 1858). Para Mayr (1998; 2005), o trabalho de Darwin (1859) compreende cinco teorias independentes, mas relacionadas: (1) a evolução propriamente dita, (2) a descendência com modificação, (3) o gradualismo, (4) a especiação (multiplicação das espécies) e (5) a seleção natural. A percepção de um mundo orgânico em constante mudança e a ideia de que todos os organismos compartilham um ancestral comum em algum momento de sua história evolutiva revolucionou o pensamento biológico no século xıx. O objetivo central de Darwin era negar o fixismo das espécies e sua criação em separado (cf. Ruse \& Travis, 2009).

A introdução da ideia de uma árvore da vida nas ciências biológicas, somada às proposições acerca dos mecanismos pelos quais a evolução ocorria, implicou em reconsiderações fundamentais para as classificações biológicas. A visão ainda vigente de uma scala naturae (escala da natureza) foi paulatinamente substituída pela noção de uma grande e única árvore da vida, uma vez que todas as formas de vida existentes assemelham-se em algum grau (ascendência comum). Coube à sistemática a busca pelos "parentes" mais próximos a todos os grupos e a reconstrução dos seus ancestrais comuns (cf. Mayr, 1998). Segundo Darwin, 
o arranjo dos táxons deve ser estritamente genealógico, mas a quantidade de diferenças em vários ramos ou grupos, ainda que unidos no mesmo grau em sangue de seu progenitor ancestral, pode diferir enormemente e isso deve ser considerado no escalonamento. Os graus de modificação que os diferentes grupos sofrem devem ser expressos em diferentes categorias (Darwin, 1859, p. 479-80).

A despeito do trabalho de Darwin (1859), Wallace (1855) tem prioridade em explicar evolutivamente a existência das categorias taxonômicas supragenéricas. Ele foi o pioneiro em temporalizar as classificações, explicando a quantidade de diferenças morfológicas por diferentes origens no tempo. Os dois critérios citados por Darwin - a genealogia e o grau de semelhança - foram incorporados pelas classificações biológicas como peças-chave de suas análises, dado o interesse pelo entendimento da história evolutiva dos organismos. Inúmeros sistematas voltaram-se para o estudo das relações de parentesco entre os organismos, e a escola conhecida como sistemática ou taxonomia evolutiva tornou-se a mais popular nas décadas de 1930-1950 (cf. Mayr et al., 1953; Mayr \& Provine, 1980). Para Mayr (2008), ela trazia a única representação passível de satisfazer ambos os critérios estabelecidos por Darwin para uma classificação consistente.

Essas classificações reuniam os grupos e os representavam em um diagrama de árvore, apresentando as relações de parentesco entre as linhagens e suas taxas de divergência morfológica (demonstradas respectivamente pela proximidade dos ramos e diferença de tamanhos dos mesmos). O objetivo era seguir à risca a premissa de Darwin ao determinar que o conhecimento da filogenia dos grupos por si só era insuficiente na proposição de uma classificação, pois, ainda que unidos por caracteres homólogos, os ramos evoluíam e divergiam em taxas muito diferentes (Mayr et al., 19533; Mayr, 2008). Tal desigualdade deveria ser levada em conta na determinação do posicionamento hierárquico.

Em outras palavras, para que um táxon fosse considerado um grupo natural monofilético, deveriam ser analisadas também as características adaptativas conquistadas ao longo da história evolutiva do grupo, atribuindo-lhes valores diferenciados. Assim, os atributos relacionados às grandes adaptações possuiriam um valor evolutivo/ adaptativo superior às características compartilhadas que uniriam os ramos, evidenciando uma disparidade morfológica, fisiológica ou comportamental, tal que justificaria a elevação do táxon a uma nova categoria hierárquica.

Esse método foi amplamente empregado até a metade do século xx, mas, à medida que novos estudos e propostas de classificação foram sugeridos, suas deficiências tornaram-se aparentes. A incorporação de conhecimentos prévios dos organismos e a pesagem a posteriori de atributos mediante observações a respeito de sua história 
Sistemátiga filogenétiga henNigiana: ReVolução ou mudança...

evolutiva resultavam em hipóteses filogenéticas não consensuais e em um subjetivismo que impedia sua "testabilidade", além de basear-se excessivamente na autoridade do pesquisador (cf. Santos, 2008). A despeito de trabalharem com o mesmo grupo de organismos, raramente dois taxonomistas clássicos assumiam as mesmas condições sobre os caminhos da evolução (cf. Lipscomb, 1998), o que levava à obtenção de hipóteses distintas.

Na década de $195^{\circ}$, dois métodos desvincularam os critérios de genealogia e de grau de similaridade, referidos na taxonomia evolutiva, para resolver a falta de rigor dos estudos filogenéticos até então realizados (cf. Hull, 1988; Santos, 2008). A taxonomia numérica, posteriormente chamada apenas fenética, propunha o agrupamento de organismos fenotipicamente semelhantes, isentando o sistemata de conhecimento evolutivo prévio e excluindo de suas atribuições qualquer diferenciação entre os caracteres observados (tais proposições sobre o processo evolutivo acrescentavam ambiguidade às análises e deveriam ser descartadas). Segundo a concepção dos feneticistas, o objetivo das atividades classificatórias seria apenas o de catalogar e facilitar o acesso às informações sobre a diversidade biológica, pois "as estimativas da "verdadeira' afinidade, no sentido filogenético, são lógica e historicamente posteriores às estimativas de similaridade global" (Cain \& Harrison, 1958, p. 86); as classificações deveriam ser elaboradas por métodos estatísticos claros e precisos. Contudo, como apontado por Santos (cf. 2008), a objetividade do método era ilusória, dado que a própria escolha dos caracteres a serem comparados dependia do observador. Desse modo, a fenética desviou-se muito da classificação biológica de fato (cf. Hull, 1988), uma vez que os feneticistas não levavam a evolução em conta para a construção dos seus fenogramas, contrariando, ou ao menos desconsiderando, a ideia darwiniana de que o processo evolutivo é o responsável pelo padrão hierárquico presente de similaridades no mundo natural (cf. Darwin, 1859).

Contrariamente, a sistemática delineada em Hennig (1950) e modificada em Hennig (1966) tinha como base para a definição dos seus agrupamentos naturais a história evolutiva dos grupos. Se um dos principais preceitos da teoria da evolução dizia respeito à ancestralidade comum, e somente com a reconstrução desses ancestrais é que se poderia inferir com propriedade a história evolutiva dos organismos, fósseis e viventes, era sensato que as classificações biológicas refletissem, antes de qualquer outro aspecto, as relações de parentesco entre os seres vivos e utilizassem o conceito de ancestralidade comum como fundamento para a identificação do monofiletismo. Esse era o mote do método de Hennig.

A metodologia filogenética consistia na observação de certos atributos nos diferentes organismos seguida da formulação de hipóteses de homologia, que seriam então confrontadas posteriormente no chamado teste de congruência (cf. Nelson \& 
Platnick, 1981; Farris, 1983), para o estabelecimento das relações de parentesco. Eram esses caracteres homólogos que sugeririam a ascendência comum. O refinamento da sistemática filogenética em relação à taxonomia evolutiva estava em discriminar caracteres primitivos (plesiomórficos) de derivados (apomórficos), e estabelecer relações de parentesco apenas a partir do compartilhamento dessas apomorfias, a fim de distinguir as homologias das convergências e determinar os grupos monofiléticos (no sentido cladístico), que são os únicos que realmente respeitam o conceito da ancestralidade comum (cf. Santos, 2008). Assim, o sistemata hennigiano identifica um clado natural como a reunião da espécie tronco (ancestral) mais recente e de todos os seus descendentes, determinada a espécie pela presença de caracteres compartilhados exclusivamente pelos descendentes (sinapomorfias), independente do grau de divergência que possa existir.

O escalonamento (ou hierarquia) originado por esse método acontece naturalmente, refletindo a história evolutiva e estabelecendo as relações de grupo-irmão entre os grupos-naturais, isto é, os clados. A forma precisa pela qual a análise cladística definiu a relação biológica de parentesco (o táxon A está mais próximo de B em relação a $\mathrm{C}$ ), ordenando as sinapomorfias de modo a obter uma classificação dos táxons consistente com sua genealogia, calcada no princípio da parcimônia (cf. Hennig, 1966; Farris, 1983), reflete a grande contribuição de Hennig para a sistemática biológica: a formulação de um método propriamente dito, testável, não arbitrário e reflexivo da realidade natural, representada em dendogramas ramificados, chamados cladogramas (que correspondem a conjecturas sobre as relações de parentesco resultantes do processo evolutivo). Em princípio, quaisquer características observadas em organismos possuem o potencial de fornecer evidências de relação de parentesco. No entanto, as evidências mais objetivas são derivadas daqueles atributos que são hereditários e intrínsecos dos organismos, porque eles refletem a continuidade biológica entre ancestral e descendente (cf. Hennig, 1966). A reconstrução dessas relações de parentesco pode ser repetida e testada por conta do sistema congruente e sólido elaborado por Hennig.

Não é rara a referência à sistemática filogenética como o grande paradigma da história da taxonomia e sistemática (cf. Hull, 1988; Williams \& Forey, 2004; Schuh \& Brower, 2009). Isso se deve em parte ao seu método e a sua importância na construção de sistemas classificatórios com grande conteúdo informativo, responsáveis por proporcionar as bases essenciais ao estudo da biologia comparada (cf. Santos, 2008), algo que, até então, não existia em nenhuma outra proposta de sistematização da diversidade biológica. 
Sistemátiga filogenétiga HenNigiana: ReVolução ou mudança...

\section{Ruptura ou mudançA DENTRo do PARAdigma?}

Segundo Kuhn (1962), uma revolução científica desarticula a atividade científica normal, promovendo a aceitação de uma nova teoria (ou paradigma), incompatível com a anteriormente estabelecida por não se tratar de uma adaptação ou um incremento a ela, e sim de uma completa reconstrução do conhecimento posto. Por atividade científica normal entende-se o período de pesquisa e produção de trabalhos decorrentes de um paradigma estabelecido, cujo objetivo não é outro senão encorpá-lo e sustentá-lo. Segundo esse raciocínio, quando Darwin e Wallace propuseram a teoria da evolução, questões antes modeladas por premissas ad hoc para satisfazer os preceitos vigentes (como o fixismo das espécies e o transformacionismo gradual progressivo) teriam recebido explicações e evidências tão conclusivas que não mais poderiam enquadrar-se em qualquer outro modelo explicativo, iniciando uma discussão que acabou culminando em uma verdadeira revolução no pensamento científico. Como foi dito anteriormente, o aparecimento da sistemática filogenética é considerado por alguns como uma ruptura de paradigmas (cf. Terra, 2010), mas uma análise mais detalhada mostra que o modelo de revolução kuhniano não se encaixa com perfeição na história da sistemática antes e depois de Hennig.

Kuhn (1962) defende a visão de que após as revoluções, novas abordagens dos fenômenos naturais emergem nas comunidades científicas e, devido ao caráter incomensurável advindo de suas particularidades culturais (por exemplo, linguagens, propósitos e metodologias distintas), elas possibilitam o crescimento do conhecimento acerca dos problemas e questões levantadas pela comunidade científica. A visão kuhniana nega a utilização do conceito de verdade como correspondência, uma vez que os paradigmas são incomensuráveis e só se traduzem em verdade ou falsidade dentro de sua comunidade específica (cf. Mendonça \& Videira, 2007). Em outras palavras, não há comunicação entre as teorias científicas.

Os paradigmas são considerados incomensuráveis uns com os outros, já que eles não compartilham termos (com o mesmo significado) nem aceitam os mesmos corpos de fatos. Cada paradigma reconhece seus próprios problemas distintos e proclama seus próprios padrões de solução (Hung, 2006, p. 5).

A referência à incomensurabilidade assume que há regras e valores somente aplicáveis dentro do próprio arcabouço teórico-conceitual do paradigma, o que impediria a comparação entre paradigmas rivais. Não seria possível, portanto, falar em teoria certa ou errada, superior ou inferior, mediante a apresentação empírica de um resul- 
tado negativo em relação ao esperado, devido à impossibilidade de comparação entre duas teorias distintas (cf. Kuhn, 1962). Para O’Hear (1997), Kuhn reproduz a visão de conhecimento científico de Pierre Duhem (1956), acrescida de um componente histórico, que nos diz que uma teoria não existe por si só, singularmente, mas na verdade compreende um conjunto de informações secundárias (ou auxiliares) que, juntas e contextualizadas, dão estrutura à teoria "principal”. Assim, a obtenção de um resultado desfavorável, ou contrário ao esperado, não é suficiente para a aceitação de um novo paradigma em detrimento do antigo, pois eles compõem e inserem-se em universos diferentes; pode-se apenas inferir que alguma de suas informações auxiliares está errada. Essa visão relativiza o conceito de verdade científica (cf. Vieira \& Fernández, 2006; Sokal \& Bricmont, 2010 [1999]). Para Hung (2006), a incomensurabilidade kuhniana é um passaporte para o relativismo, pois torna inviável comparar os méritos científicos de paradigmas ditos contrários, uma vez que eles não compartilhariam os termos conceituais ou os dados empíricos.

Ao propor seu método, Hennig alcançou um sistema coerente e eficiente por meio de ajustes na maneira como as hipóteses de parentesco eram então construídas, a começar pelos seus propósitos: “(...) a construção de um cladograma de acordo com os princípios da sistemática filogenética resulta em um sistema bastante diferente dos vários tipos de classificação possíveis" (Hennig, 1975, p. 246). Isso possibilita a reconstrução mais fidedigna do ancestral comum e seus descendentes modificados. Porém, a despeito dos avanços introduzidos, a sistemática filogenética compartilha o mesmo universo teórico que a taxonomia evolutiva. A teoria fundamental que embasa as duas "escolas" sistemáticas é a mesma: a evolução orgânica, juntamente com todos os seus pressupostos (ancestralidade comum, descendência com modificação, variação pré-existente etc.). Ambas as escolas de classificação "falam a mesma língua" e valem-se das construções de árvores evolutivas para expressar seus apontamentos.

Por ter enxergado as deficiências da visão darwinista sobre a categorização dos organismos, seguida da incompletude da prática adotada pelos sistematas evolutivos, Hennig pôde refinar os parâmetros necessários à formulação de hipóteses filogenéticas. Não se tratou, portanto, da criação de um modelo completamente distinto do anterior, e sim da criação de um método aplicável ao mesmo modelo, uma vez que

todo estilo de pensamento contém descendentes do desenvolvimento histórico de vários elementos de outros estilos. Provavelmente, muito poucos conceitos completamente novos são formados sem relação qualquer a um estilo de pensamento anterior. Desse modo, nasce uma conexão histórica entre os estilos de pensamento (Fleck, 1986 [1935], p. 75). 
Essa é uma das razões pela qual o surgimento da sistemática filogenética não se enquadra no conceito de revolução científica kuhniana. Ainda que o conjunto de regras e valores atrelados a um paradigma especifique uma "teoria central" de tal modo que não possa ser aplicável a nenhuma outra, há que se lembrar que o seu estabelecimento significa a aceitação de um modelo teórico como o mais representativo ou próximo dos fenômenos naturais (naquele momento e contexto em que se desenvolve), e que a eficiência desse modelo é mensurável. Dessa forma, as hipóteses filogenéticas derivadas tanto da análise cladística quanto da sistemática evolutiva são perfeitamente comparáveis uma vez que se definam quais critérios serão avaliados. De fato, as conjecturas que representam as relações de parentesco entre quaisquer organismos procuram aproximar-se da árvore da vida, que é única, por mais complexas que sejam as inter-relações entre seus ramos. Como não temos conhecimento completo dela, à sistemática biológica vão interessar os estudos que possibilitem o aumento das informações a respeito da história evolutiva dos grupos biológicos, concordantes com sistemas classificatórios que facilitem o acesso a essas informações (cf. Marques \& Lamas, 2006) e congruentes com padrões obtidos a partir de diferentes análises (cf. Capellari \& Santos, 2012). Quanto maior a congruência entre hipóteses filogenéticas distintas, menores as chances de que as similaridades sejam fruto do acaso e não de um processo histórico (cf. Llorente et al., 2002). Os argumentos hennigianos são os que melhor satisfazem tais condições.

\section{Arcabouģos Gonceituais gompartilhados}

Em 1935, Ludwick Fleck, médico polonês especializado em microbiologia e imunologia, propôs em seu livro uma epistemologia das ciências que levasse em conta os inúmeros fatores desconhecidos que se apresentam em conjunto a uma teoria, recusando assim a utilização de argumentos unicamente racionais para sua aceitação ou refutação (Fleck, 1979 [1935]). Para Fleck, a produção de conhecimento girava em torno da transitoriedade de ideias e teorias diferentes entre grupos de indivíduos guiados pelo mesmo estilo de pensamento. A interação entre esses coletivos propiciaria a troca de informações, mudanças graduais e subsequente transformação, instauração e extensão desses estilos de pensamento. "Não podemos nos desvincular de um passado que segue hoje vivo, em conceitos herdados, na forma de conceber os problemas" (Fleck, 1986 [1935], p. 67). Admite-se a coexistência de múltiplos estilos de pensamento que, devido às experiências e práticas de seus coletivos e ao relacionamento intercoletivo, modificam-se ao longo do tempo em um novo estilo, nem melhor nem pior que o anterior, mas com maior possibilidade de correspondência com as demandas do período. 
Assim como Kuhn (1962), o pensamento fleckiano enfatiza a consideração de fatores externos interferindo no conhecimento, como as subjetividades dos coletivos de pensamento e as condições histórico-sociais em que este se insere. Fleck partia de suas observações da medicina, julgando impossível obter uma visão global de certa doença, mas apenas visões parciais (a partir da bioquímica, fisiologia, genética, psicologia, imunologia) que, ainda que interagissem entre si, compunham um ponto de vista particular (cf. Löwy, 1994). Ele extrapolou essa analogia à construção e desenvolvimento do pensamento científico, caracterizando-o com certo grau de incomensurabilidade que, mais tarde, seria fortemente defendido por Kuhn (cf. 1962; 2006). Porém, a forma pela qual tratou o desenvolvimento do conhecimento como uma atividade social dos coletivos de pensamento, em que a promoção de um novo estilo de pensamento ocorre sem rupturas ou revoluções, de maneira gradual por meio de transformações dos estilos antigos, difere de Kuhn e aproxima-se da visão popperiana para o avanço científico.

Popper (1959) afirma que o critério para o status científico de uma dada teoria é sua falseabilidade, ou seja, sua característica de ser testável. A verdade científica é uma só: a prática científica é racional e não há espaço para subjetividade, a hipótese científica deve ser suscetível a todo e qualquer teste empírico, podendo ser refutada a qualquer momento. Popper (1999 [1973]) compara o desenvolvimento do conhecimento científico à teoria de Darwin, chamando-o de seleção natural de hipóteses. Aquelas com maior aptidão para resistir às duras críticas perdurariam por mais tempo, pois pressuporiam a ideia de verdade como correspondência com os fatos. Na ilustração de Popper para a árvore do conhecimento, inúmeras hipóteses surgiriam e apenas as "mais aptas", isto é, aquelas que melhor resolvem um determinado problema em relação a suas concorrentes, cresceriam rumo à unificação em um tronco comum. Essa convergência de ideias é determinada pela capacidade de raciocínio e pela linguagem humana, que permitem o estudo racional dos problemas da ciência, bem como a busca de soluções alternativas e a verificação da pertinência dos testes aplicados.

Para fins de exemplo, consideremos duas árvores que apontam as relações de parentesco utilizando os mesmos táxons terminais, uma construída no método hennigiano e outra seguindo os preceitos da taxonomia evolutiva. No cenário gradista, a árvore apresentada separa dois táxons irmãos em grados diferentes (na figura 1A, "Reptilia" e "Aves"), justificando-se por meio da distância evolutiva existente entre eles, dada pela atribuição de valores mais ou menos altos às características exclusivas dos táxons (no exemplo citado, a presença de penas e capacidade de voo suportaria a existência de um grado "Aves" separados dos répteis). Além disso, a árvore traz um fóssil, o Archaeopteryx, como o ancestral das aves modernas - o que é injustificável em termos filogenéticos, uma vez que não há maneira científica de imputar-se o status de 


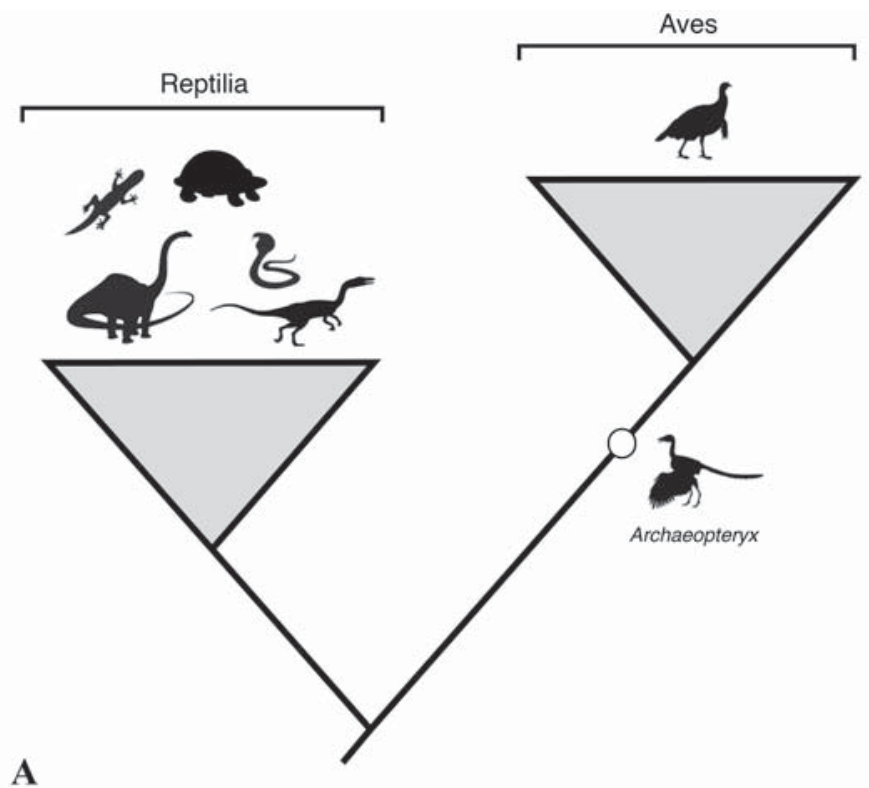

A

Reptilia

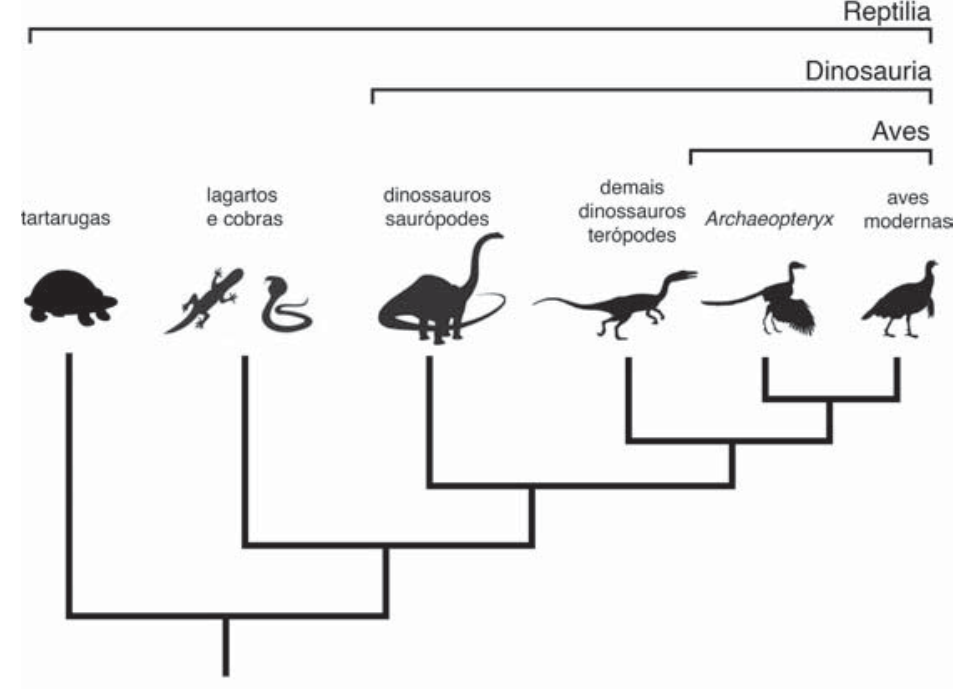

B

Figura 1. Hipóteses filogenéticas para explicar as relações de parentesco entre os répteis e as aves. A. Árvore evolutiva nos moldes da taxonomia evolutiva. Note que Archaeopteryx é posicionado como ancestral das aves modernas. A diferença no tamanho dos ramos representa a quantidade presumida de alterações durante a evolução até o surgimento do determinado grado; B. Cladograma nos moldes da sistemática filogenética. Reptilia só é grupo-natural se incluir as Aves. Archaeopteryx é grupo-irmão das aves recentes (mas não o ancestral delas), uma vez que todos os táxons terminais - fósseis ou viventes - são tratados da mesma forma no método de Hennig. 
ancestral a qualquer táxon, seja ele extinto ou vivente (cf. Hennig, 1966; Nelson \& Platnick, 1981). Uma reprodução dessa análise por um segundo sistemata, ainda sob os conceitos gradistas, poderá produzir uma topologia distinta, com os táxons reorganizados em outros grados, refletindo a importância dada a outros dos seus atributos, diferentemente do que fizera o primeiro autor. (Pode-se considerar, por exemplo, a presença de penas como uma característica distinta de um grado contendo todos os dinossauros emplumados, que incluiria, portanto, o Archaeopteryx e também as aves modernas). É possível que um terceiro autor, trabalhando com os mesmos grupos taxonômicos, chegue a uma hipótese distinta das duas primeiras propostas. Ainda que os critérios considerados na análise sejam os mesmos (ancestralidade comum, homologias, divergência fenotípica), suas percepções pelos sistematas são subjetivas (cf. Mendonça \& Videira, 2007), uma vez que as classificações encontram-se arraigadas às concepções e ao conhecimento prévio de seus autores de modo que não se pode esperar congruência entre duas ou mais delas, do ponto de vista das relações de parentesco entre os organismos considerados (cf. Santos, 2008). Como não há medida objetiva para considerar-se a importância evolutiva de um dado atributo ou conjunto deles, e como a taxonomia evolutiva parte do pressuposto de que tal definição é fundamental para a determinação dos grados, as árvores evolutivas oriundas desse método incluem um alto grau de arbitrariedade - as árvores evolutivas da sistemática clássica dependem em muito da autoridade do pesquisador que as propõe (cf. Hull, 1988).

Contudo, se três autores diferentes usarem a metodologia apresentada por Hennig para identificar as relações de parentesco entre os mesmos grupos taxonômicos, a chance de obterem hipóteses diferentes é, de maneira geral, reduzida. Há obviamente certo grau de subjetividade no levantamento dos caracteres utilizados para o procedimento filogenético analítico. Entretanto, é o teste de congruência entre esses caracteres (cf. Farris, 1983; Schuh \& Brower, 2009) que determinará se existe uma hipótese robusta e bem resolvida das relações de parentesco entre os táxons considerados, não uma escolha ad hoc sobre a relevância ou não de uma dada estrutura para a evolução, como acontece na taxonomia evolutiva. Além disso, para a sistemática hennigiana, todos os táxons terminais são tratados da mesma forma, o que significa não imputar a nenhum grupo a condição de ancestral, mesmo que ele corresponda a um organismo extinto. Os fósseis são parte da hierarquia da natureza e sujeitos aos mesmos limites de interpretação que os organismos vivos (na figura ıB, Archaeopteryx é grupo-irmão das aves modernas, não ancestral direto das mesmas). Além da metodologia seguida pelos filogeneticistas ser consistente e imparcial, as hipóteses filogenéticas são passíveis de teste à luz de informações exteriores - como diferentes classes de evidências -, que é o princípio da iluminação recíproca de Hennig (cf. Capellari \& Santos, 2012). Isso não deve ser visto em um sentido verificacionista simples (cf. Vogt, 2008): quanto maior a 
congruência de uma hipótese de relações de parentesco com outras obtidas, por exemplo, a partir da comparação de atributos distintos ou outras fontes de evidências, maior o seu poder explanatório (cf. Llorente et al., 2002). A incorporação dessas informações adicionais aperfeiçoa a hipótese e a torna mais próxima ou mais condizente com a história evolutiva.

Em virtude da consistência teórica e do suporte empírico demonstrados pela hipótese hennigiana e do caráter especulativo da proposição gradista, deveríamos refutar esta última. Popper (1999 [1973]) entende o crescimento do conhecimento como pequenos avanços de antigos para novos problemas, em que, na impossibilidade de justificar ou afirmar as soluções encontradas, o mais correto é colocá-las à prova por meio de críticas racionais e então adotar experimentalmente as que suportarem melhor tais críticas e demonstrarem maior poder explicativo. No entanto, se uma teoria até então considerada robusta é falseada por uma única observação, dado o contexto em que ela se insere, é razoável relevar suas dificuldades em um primeiro momento, caso contrário a ciência não seria viável (cf. Sokal \& Bricmont, 2010 [1999]). Esse, todavia, não é o caso do exemplo supracitado, já que a taxonomia evolutiva é intrinsicamente falha, pois falta a ela a precisão conceitual e a repetibilidade de um método de reconstrução, que só foram aparecer com Hennig (cf. Santos, 2008). Admitir hipóteses filogenéticas derivadas das duas "escolas" citadas anteriormente, aceitando a coexistência de múltiplas soluções na impossibilidade de comprovação absoluta de qualquer uma delas, insere um componente relativista não condizente com o objetivo central da sistemática biológica, que é a reconstrução da história evolutiva dos organismos.

Kuhn direciona a seleção entre teorias científicas para algo além da cientificidade das metodologias e das investigações, compreendendo também certa habilidade dos cientistas em estabelecer seus modelos e defender sua prática na ciência normal (cf. Vieira \& Fernández, 2006). Na concepção kuhniana, as mudanças de paradigmas passam a ser determinadas não apenas por fatores empíricos (Sokal \& Bricmont, 2010 [1999]). Para ele,

os cientistas individuais abraçam um novo paradigma por toda uma sorte de razões e normalmente por várias delas ao mesmo tempo. Algumas dessas razões - por exemplo, a adoração ao Sol que ajudou a fazer de Kepler um copernicano - encontram-se inteiramente fora da esfera aparente da ciência (Kuhn, 1962, p. 193).

Se pensarmos no período imediatamente posterior ao surgimento de uma nova teoria, quando ainda não existem estudos abundantes calcados nos seus princípios e, consequentemente, não há comprovações empíricas de seu sucesso, resta pouco mais que o discurso de seus mentores e partidários sobre sua eficiência em satisfazer as ques- 
tões que estavam sendo negligenciadas pela teoria antiga. A adesão dos cientistas ao novo pode muito bem ter lugar antes que as provas empíricas tornem-se completamente convincentes; é plausível que a ligação de alguns nomes veteranos (ou que possuam alguma influência na academia) a uma nova teoria instigue a curiosidade dos demais em testá-la. Todavia, o estabelecimento e plena aceitação de uma teoria não tem relação exclusiva com fatores externos à capacidade e cientificidade das suas proposições, pois esse status é alcançado pelo reconhecimento posterior do poder explanatório de seu corpo conceitual e metodológico. Esse é exatamente o caso da sistemática filogenética. Treze anos após a publicação de seu principal trabalho (Hennig, 1966), os sistematas Don Rosen, Gareth Nelson e Colin Paterson expuseram com clareza as mudanças incorporadas pela perspectiva cladística, naquele momento já dominante na comunidade acadêmica, e que se tornou praticamente unanimidade entre os praticantes da sistemática a partir dos anos 1980 e da publicação de trabalhos importantes como os de Nelson e Platnick (1981) e Farris (1983). Eles comentam que, por meio da sistemática filogenética, “(...) a ideia de evolução orgânica foi mudada de uma narrativa sobre a história da vida [como o era nos tempos da taxonomia evolutiva] para uma teoria científica sobre como a natureza está ordenada em uma estrutura hierárquica particular" (Rosen; Nelson \& Paterson apud Hennig, 1979, p. ix).

Terra (2010), em sua análise do cenário histórico em que a sistemática biológica estava inserida na segunda metade do século xx, concluiu ser evidente a ocorrência de uma revolução kuhniana a partir da introdução do método hennigiano, que teria triunfado de forma inconteste sobre a taxonomia de Mayr e outros contemporâneos. No entanto, dadas as características intrínsecas do método de Hennig e sua posição entre as "escolas" de classificação, não houve ruptura revolucionária no sentido kuhniano na história da sistemática. Como discutido, a sistemática filogenética compartilha a mesma abordagem e está fundamentada nos mesmos princípios teóricos advogados pela taxonomia clássica, que remontam ao conceito de descendência com modificação a partir de um ancestral comum de Wallace $\left(1855,185^{8}\right)$ e Darwin (1858, 1859). Ambas as "escolas" reclamam para si a interpretação correta da história de vida dos organismos segundo a teoria da evolução, sendo possível, e natural, confrontar e analisar criticamente seus resultados. O período que caracteriza a diminuição da influência da taxonomia evolutiva nos trabalhos de sistemática biológica e a ascensão da metodologia hennigiana não corresponde, portanto, a uma completa reconstrução de pensamento, desconectada de vínculos maiores com a teoria antes vigente, e sim de uma transformação substancial de um método pouco repetível para outro mais robusto e objetivo dentro de um mesmo paradigma. Como argumenta Popper (1999 [1973]), algumas conjecturas mais aptas a resistir às críticas perduram por mais tempo. Quanto maior a 
Sistemátiga filogenétiga henNigiana: ReVolução ou mudança...

resistência, maior a correspondência dessas hipóteses com os fatos. No caso da sistemática biológica, maior será a proximidade entre os cenários representados nos cladogramas com o que de fato ocorreu na história evolutiva dos grupos sob escrutínio.

Ao propor sua interpretação da história evolutiva orgânica segundo a ascendência comum, Hennig (cf. 1950, 1966) solucionou o problema de interpretação do conhecimento biológico sob a perspectiva evolutiva, criando uma metodologia que possibilita a delimitação de grupos naturais com um grau de predição aproximadamente verdadeiro. Essa "confiança" advém do embasamento da sistemática filogenética no conceito de monofiletismo, definido por Hennig, que permite a recuperação e organização do conteúdo informativo sobre a história evolutiva das linhagens (cf. Santos, 2008). Em suma, dada a importância da sistemática hennigiana na construção de sistemas classificatórios com alto poder de explicação, que não se apoiam em arbitrariedades e hipóteses não testáveis (cf. Santos, 2008), é quase irresistível não ceder à tentação de tratá-la como revolucionária. A definição convencional de revolução - mudança completa, reforma, transformação, abandono de ideias, sistemas e métodos tradicionais para adotar novas técnicas - parece perfeitamente compatível com a proposta da sistemática filogenética. Contudo, sua caracterização como revolucionária entendida nos termos kuhnianos desconsidera que tanto a proposta de Hennig quanto a dos sistematas e paleontólogos da teoria sintética da evolução (cf. Mayr et al., 1953; Mayr, 1998) tomam por base os fundamentos da teoria evolutiva.

\section{Considerações finais}

O método filogenético preocupa-se com questões relativas à corroboração e refutação de conjecturas sobre a evolução de caracteres e com critérios usados para o estabelecimento de hipóteses científicas válidas (cf. Santos \& Calor, 2008). Um cladograma derivado de uma fonte de evidência não pode ser falseado por outro que se baseia em um conjunto de atributos distintos. Apesar disso, uma hipótese que se mostre congruente com outras oriundas de diferentes classes de evidências (por exemplo, morfologia e dados moleculares), no sentido de apresentar as mesmas relações de parentesco, possui elevado poder explanatório (cf. Capellari \& Santos, 2012).

Para Vogt (2008), um cladograma resultante de uma análise utilizando o método hennigiano apoia-se, em parte, em hipóteses auxiliares provenientes de informações que não podem ser falseadas, tampouco consideradas verdades, pois fogem da esfera do pensamento dedutivo. Se, para Popper (1959), uma teoria científica é passível de falseamento caso ela proíba a ocorrência de certos eventos ou observações, as hipó- 
teses filogenéticas, por não proibirem nada e não fazerem previsões testáveis, não seriam científicas segundo o critério de demarcação popperiano. Nos cladogramas, por exemplo, não se proibe a ocorrência de homoplasias, que corresponderiam a hipóteses de homologia primária incongruentes com as demais durante a análise. Como não há nenhuma ligação dedutiva entre uma hipótese filogenética e o estado de distribuição de caracteres, não existe teste empírico para a construção dos cladogramas, de modo que eles não podem ser falseados. Para Bock (2004), as explicações histórico-narrativas têm natureza singular, não podendo ser extrapoladas como regra geral ou padrão para situações semelhantes, ocupam posição espaço-temporal definida e dependem do passado histórico de seus objetos de estudo. Nesse sentido, as hipóteses de relação de parentesco entre os grupos orgânicos são irrefutáveis, é impossível falsear uma explicação histórico-narrativa e, uma vez que as hipóteses filogenéticas são "retratos" da evolução dos organismos e dos seus atributos, o seu grau de confiança não deve ser delimitado pela possibilidade de falseamento, mas sim pela adição de informações congruentes que as confirmem. Assim, não existiria justificativa plausível para explicar a preferência entre diferentes cladogramas, porque não existiria nenhum método de quantificação dos "graus de corroboração".

Entretanto, algumas inferências são mais razoáveis que outras. Ao testarmos exaustivamente os argumentos (explicações nomológico-dedutivas e observações empíricas) de uma hipótese filogenética, como propõe Bock (2004), estamos submetendo-os ao pensamento crítico consciente de modo a eliminar quaisquer dúvidas não razoáveis e suprimir considerações irracionais. Nesse processo, é possível confrontarmos nossa conjectura à luz de informações externas e aperfeiçoá-la, tornando-a resistente e conferindo-lhe maior plausibilidade. Nesse sentido, pode-se dizer que as hipóteses filogenéticas são proposições sobre as relações de parentesco entre os grupos biológicos em questão, representadas como a opção mais válida dadas as evidências disponíveis, porém sujeitas a testes e confrontos com evidências adicionais (cf. Wiley, 1975; Farris, 1983; Brower et al., 1996; Hull, 1988; Kluge, 1997, 1998; Siddall \& Kluge, 1997; Faith \& Trueman, 2001; Faith, 2004). O fato de hipóteses filogenéticas não se enquadrarem em sentido estrito às concepções popperianas de modo algum significa que a sistemática de Hennig não seja científica (cf. Vogt, 2008). Sua metodologia, seus testes e seu embasamento teórico são maduros, racionais e coerentes. A despeito da impossibilidade de serem falseadas, tais hipóteses podem ser testadas à luz de outras em busca de congruência. Quanto mais congruentes entre si, mais os cladogramas aproximar-se-ão da história dos grupos estudados, e constituirão, dessa forma, cenários fidedignos do passado evolutivo (cf. Capellari \& Santos, 2012). 
Os cladogramas do método hennigiano, quando iluminados reciprocamente ao serem comparados com diferentes classes de evidência (cf. Capellari \& Santos, 2012), mostram-se muito mais robustos, como reconstrução evolutiva, que as árvores evolutivas da taxonomia de Mayr e colaboradores, o que demonstra a qualidade da sistemática filogenética, independentemente de influências alheias ao seu próprio conjunto de regras. Mesmo assim, o aparecimento da sistemática de Hennig não pode ser considerado um rompimento total com uma tradição de pesquisa anterior. Segundo Kuhn (1962), dois paradigmas são incomensuráveis, o que não acontece entre as duas "escolas" de sistemática aqui consideradas, pois ambas são baseadas na premissa da ancestralidade comum de Wallace $\left(1855,185^{8}\right)$ e Darwin $\left(185^{8}, 1859\right)$ e têm suas proposições resultantes perfeitamente comparáveis. Nas palavras do próprio Kuhn,

as mudanças revolucionárias são diferentes e bem mais problemáticas [do que as mudanças conceituais da ciência normal, do tipo cumulativo]. Elas envolvem descobertas que não podem ser acomodadas nos limites dos conceitos que estavam em uso antes de elas terem sido feitas. A fim de fazer ou assimilar uma tal descoberta, deve-se alterar o modo como se pensa, e se descreve, algum conjunto de fenômenos naturais (Kuhn, 2006, p. 25).

A despeito da propagada revolução introduzida por Hennig na sistemática biológica, ela não se enquadra no modelo kuhniano do desenvolvimento científico revolucionário e, portanto, tem que ser vista como um avanço conceitual a partir de métodos menos eficientes de organização da diversidade biológica, porém fundamentados no mesmo arcabouço teórico. Mais do que uma ruptura radical de um corpo teóricometodológico claudicante, o método hennigiano representou uma mudança estrutural na prática sistemática baseada no evolucionismo darwiniano, alçado à linha de frente das ciências biológicas pela teoria sintética da evolução dos anos 1930-1940. Não obstante, a sistemática filogenética é um método preciso, objetivo, repetível e não baseado na autoridade, características que foram cruciais para sua "sobrevivência" na luta com outras diferentes escolas de sistemática do século xx.@

Agradecimentos. Os autores agradecem sinceramente ao Prof. Nelson Papavero (MZUSP) e a dois revisores anônimos pela leitura e sugestões feitos em uma versão preliminar deste texto, que foi substancialmente melhorado na sua versão final. O trabalho foi financiado pela CAPES (Klassa) e CNPq (474511/2009-o, Santos). 


\author{
Charles Morphy Dias Santos \\ Professor adjunto de Biologia Evolutiva e Comparada dos Animais, \\ Centro de Ciências Naturais e Humanas, \\ Universidade Federal do ABC, São Paulo, Brasil. \\ charles.santos@ufabc.edu.br \\ Bruna KLASSA \\ Mestranda em Ensino, História e Filosofia da Ciência e Matemática, \\ Centro de Giências Naturais e Humanas, \\ Universidade Federal do ABC, São Paulo, Brasil. \\ bruna.santanna@ufabc.edu.br
}

\begin{abstract}
Phylogenetic Systematics, a method to reconstruct evolutionary trees created by Willi Hennig in 1955 and expanded in 1966, is often considered a new paradigm that revolutionized biological classifications when compared to former schools of systematics such as evolutionary taxonomy. Such an approach to the history of systematics is mainly based on Kuhn's view of the progress of scientific knowledge. However, we can question the validity of the revolutionary status - in the Kuhnian view - attributed to Hennigian phylogenetics. Herein, we discuss the shared attributes of phylogenetic systematics and evolutionary taxonomy, both deeply rooted in Darwin-Wallace's evolutionary theory, and why Hennig's method is a development of Mayr's and Simpson's proposals for biological classification, explicit in the synthetic evolutionary theory of the years 1930 and 1940. In this sense, they adjust to the popperian vision of a "natural selection" of scientific hypothesis. Yet, phylogenetic systematics is a robust and objective scientific method, thus having characteristics that allow it to "survive" in the struggle for existence with other schools of systematics.
\end{abstract}

KeYwords $\bullet$ Evolutionary taxonomy. Kuhn. Hennig. Paradigm. Phylogenetic systematics.

\title{
REFERÊNGIAS BIBLIOGRÁFICAS
}

Bock, W. J. Explanations in systematics. In: Williams, D. M. \& Forey, P. L. (Ed.). Milestones in systematics. Washington: CRC Press, 2004. p. 49-56.

Bowler, P. J. Evolution: the history of an idea. Berkeley/Los Angeles: University of California Press, 2003.

Brower, A. V. Z. et al. Gene trees, species trees and systematics: a cladistic perspective. Annual Review of Ecology and Systematics, 27, p. 4,23-50, 1996.

Cain, A. J. \& Harrison, G. A. An analysis of the taxonomist's judgment of afûnity. Proceedings of the Zoological Society of London, 131, p. 84--98, $195^{8}$.

Capeldari, R. S. \& Santos, C. M. D. Realism in systematics through biogeographical consilience. Cladistics, 28 , p. 170-3, 2012 . 


\section{Sistemátiga filogenétiga henNigiana: ReVolução ou mudança...}

DARWIN, C. On the tendency of species to form varieties, and on the perpetuation of varieties and species by means of natural selection. Journal of the Proceedings of the Linnean Society (Zoology), 3, p. 45-62, $185^{8}$.

. On the origin of species by means of natural selection or the preservation of favored races in the struggle for life. London: Murray, 1859.

Dunem, P. The aim and structure of physical theory. Princeton: Princeton University Press, 1956.

FAITH, D. P. From species to supertrees: popperian corroboration and some current controversies in systematics. Australian Systematic Botany, 17, p. 1-16, 2004.

Faith, D. P. \& Trueman, J. Towards an inclusive philosophy for phylogenetic inference. Systematic Biology, 5 o, p. 331-50, 2001.

Farris, J. S. The logical basis of phylogenetic analysis. In: Platnick, N. I. \& Funk, V. A. (Ed.). Advances in cladistics. New York: Columbia University Press, 1983. p. 1-36.

FLECK, L. The genesis and development of a scientific fact. Chicago: University of Chicago Press, 1979 [1935]. La génesis y el desarrollo de un hecho científico: introducción a la teoria del estilo de pensamiento y del colectivo de pensamiento. Madrid: Alianza Editorial, 1986 [1935].

Gould, S. J. The structure of evolutionary theory. Cambridge: The Belknap Press, 2002.

Hennig, W. Grundzüge einer Theorie der phylogenetischen Systematik. Berlin: Deutscher Zentralverlag, 1950. Phylogenetic systematics. Urbana: University of Illinois Press, 1966.

. Cladistic analysis or cladistic classification?: a reply to Ernst Mayr. Systematic Zoology, 13, p. 1-11, 1975 .

. Phylogenetic systematics. 2. ed. Urbana: University of Illinois Press, 1979.

HulL, D. L. Science as a process: an evolutionary account of the social and conceptual development of science. Chicago: University of Chicago Press, 1988.

Hung, E. H. C. Beyond Kuhn: scientific explanation, theory structure, incommensurability and physical necessity. Aldershot: Ashgate Publishing Limited, 2006.

Kluge, A. G. Testability and the refutation and corroboration of cladistic hypotheses. Cladistics, 13 , p. 81-96, 1997.

. Total evidence or taxonomic congruence: cladistics or consensus classification. Cladistics, 14, p. $15^{1-8,} 1998$.

Kunn, T. S. The structure of scientific revolutions. Chicago: University of Chicago Press, 1962. . O caminho desde a estrutura: ensaios filosóficos, 1970-1983, com uma entrevista autobiográfica. São Paulo: Editora Unesp, 2006.

Llorente, J. et al. La distribución de los seres vivos y la historia da la Tierra. México, D.F.: La Ciencia para Todos, 2002.

Lipsсомв, D. Basics of cladistic analysis. Washington: George Washington University, 1998.

Löwr, I. Ludwick Fleck e a presente história das ciências. Manguinhos, 1, 1, p. 7-18, 1994.

Marques, A. C. \& Lamas, C. J. E. Taxonomia zoológica no Brasil: estado da arte, expectativas e sugestões de ações futuras. Papéis Avulsos de Zoologia , 46, 13, p. 139-74, 2006.

Mayr, E. O desenvolvimento do pensamento biológico. Brasília: Editora Universidade de Brasília, 1998. Biologia, ciência única. São Paulo: Companhia das Letras, 2005. Isto é biologia: a ciência do mundo vivo. São Paulo: Companhia das Letras, 2008.

MAYR, E. \& Bock, W. J. Classifications and other ordering systems. Journal of Zoological Systematics and Evolutionary Research, 40, p. 169-94, 2002.

MaYr, E. et al. Methods and principles of systematic zoology. New York: McGraw-Hill Publications, $195^{3}$.

Mayr, E. \& Provine, W. B. The evolutionary synthesis: perspectives on the unification of biology. Cambridge: Harvard University Press, 1980. 
Mendonça, A. L. O. \& Videira, A. A. P. Progresso científico e incomensurabilidade em Thomas Kuhn. Scientiae Studia, 5, 2, p. 169-83, 2007.

Nelson, G. \& Platnick, N. Systematics and biogeography: cladistics and vicariance. New York: Columbia University Press, 1981.

O’Hear, A. (Ed.). Karl Popper: filosofia e problemas. São Paulo: Editora Unesp, 1997.

Platnick, N. I. \& Funk, V. A. (Ed.). Advances in cladistics. New York: Columbia University Press, 1983.

Popper, K. The logic of the scientific discovery. New York: Basic Books, 1959. . Conhecimento objetivo. Belo Horizonte: Editora Itatiaia, 1999 [1973]. . Conjecturas e refutações. 5. ed. Brasília: Editora da Universidade de Brasília, 2008 [1980].

Ruse, M. \& Travis, J. Evolution: the first four billion years. London: The Belknap Press of Havard University Press, 2009.

Santos, C. M. D. Os dinossauros de Hennig: sobre a importância do monofiletismo para a sistemática biológica. Scientiae Studia, 6, 2, p. 179-200, 2008.

Santos, G. M. D. \& Calor, A. R. Using the logical basis of phylogenetics as the framework for teaching biology. Papéis Avulsos de Zoologia, 48, 18, p. 199-211, 2008.

Schun, R. T. \& Brower, A. V. Z. Biological systematics: principles and applications. New York: Cornel University Press, 2009.

Siddall, M. E. \& Kudge, A. G. Probabilism and phylogenetic inference. Cladistics, 13, p. 313-36, 1997.

Sokal, A. \& Bricmont, J. Imposturas intelectuais: o abuso da ciência pelos filósofos pós-modernos. Rio de Janeiro: Editora Record, 2010 [1999].

TERRA, P. S. O triunfo da cladística: a análise do embate teórico ocorrido na sistemática biológica na segunda metade do século xx. IV Seminário de História e Filosofia da Ciência. Bahia: Universidade Estadual de Santa Cruz, 2010.

Vieira, J. G. S. \& Fernández, R. G. A estrutura das revoluções científicas na economia e a revolução keysinana. Estudos Econômicos, 36, 2, p. 355-81, 2006.

Vogt, L. The unfalsifiability of cladograms and its consequences. Cladistics, 24, p. 62-73, 2008.

WALLACE, A. R. On the law which has regulated the introduction of new species. Annals and Magazine of Natural History, 16, p. 184-96, 1855 .

On the tendency of varieties to depart indefinitely from the original type. Proceedings of the Linnean Society of London, 3, p. $5^{3-62,18} 5^{8}$.

WiLEY, E. O. Karl R. Popper, systematics and classification: a reply to Walter Bock and other evolutionary taxonomists. Systematic Zoology, 24, p. 233-43, 1975.

Williams, D. M. \& Forey, P. L. (Ed.). Milestones in systematics. Washington: CRC Press, 2004. 